\title{
Calidad bacteriológica de la leche cruda bovina almacenada en el centro de acopio Mocha. Tungurahua. Ecuador
}

\author{
Bacteriological quality of raw bovine milk stored at the \\ Mocha collection center. Tungurahua. Ecuador
}

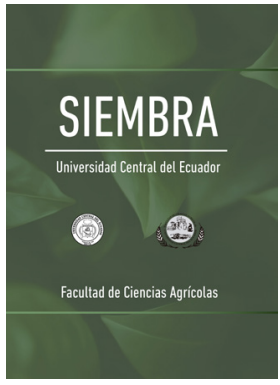

Ana Karina Albuja Landi ${ }^{1,4}$, Sandra Noemí Escobar Arrieta ${ }^{2,4}$, Félix Daniel Andueza Leal ${ }^{3,4}$

\footnotetext{
${ }^{1}$ Escuela Superior Politécnica del Chimborazo. Facultad de Ciencias. Panamericana Sur km 1 1⁄2. Código postal EC060155. Riobamba. Chimborazo. Ecuador

凶ana.albuja@espoch.edu.ec

(D. https://orcid.org/0000-0002-8774-279X

${ }^{2}$ Escuela Superior Politécnica del Chimborazo. Facultad de Ciencias. Panamericana Sur km 1 112. Código postal EC060155. Riobamba. Chimborazo. Ecuador.

凶kasandraea@gmail.com

Q https://orcid.org/0000-0002-3347-0282

${ }^{3}$ Universidad Central del Ecuador. FIGEMPA. Ciudadela Universitaria, Benjamín Chávez y Jerónimo Leitón. Código postal 170129. Quito. Pichincha. Ecuador.

$\bowtie$ fdandueza@uce.edu.ec

(1) https://orcid.org/0000-0002-9046-8883

${ }^{4}$ Universidad de los Andes. Facultad de Farmacia y Bioanálisis. Postgrado en Química de medicamentos. Mención Biotecnología. Prolongación Avenida Principal Santa Juana. Sector Campo de Oro. Código postal. 5101. Mérida. Estado Mérida. Venezuela.
}

*Autor de correspondencia: fdandueza@uce.edu.ec

\section{SIEMBRA}

https://revistadigital.uce.edu.ec/index.php/SIEMBRA ISSN-e: $2477-8850$

ISSN: $1390-8928$

Periodicidad: semestral

vol. 8, núm. 2, 2021

siembra.fag@uce.edu.ec

DOI: https://doi.org/10.29166/siembra.v8i2.3176

Esta obra está bajo una licencia internacional Creative Commons Atribución-NoComercial

\section{Resumen}

La calidad bacteriológica de la leche cruda bovina tiene implicaciones económicas y sanitarias muy importantes para el desarrollo agropecuario de los países. En este sentido, se realizó el presente trabajo para conocer la calidad bacteriológica de la leche cruda bovina almacenada en un centro de acopio de la provincia de Tungurahua, Ecuador. Se analizaron un total de 20 muestras de leche obtenidas durante las épocas de invierno y verano de los tanques de almacenamiento de los transportes de las rutas, así como del tanque del centro de acopio. Se cuantificaron los siguientes indicadores de calidad bacteriológica: bacterias aerobias mesófilas, Enterobacteriaceae, Staphylococcus y Salmonella. Estos indicadores se ajustan a las normas ecuatorianas INEN para leche cruda bovina, utilizando los medios de cultivos y las condiciones de incubación indicados en las normas para cada uno de los grupos bacterianos evaluados. En la época de invierno se obtuvieron valores promedios para las bacterias aerobias mesófilas de 1,22 x $10^{8} \mathrm{UFC} / \mathrm{mL}$, Enterobacteriaceae $7,90 \times 10^{5} \mathrm{UFC} / \mathrm{mL}$ y Staphylococcus $6,12 \times 10^{4} \mathrm{UFC} / \mathrm{mL}$. En la época de verano los valores promedios obtenidos fueron bacterias aerobias mesófilas 8,07 x $10^{6} \mathrm{UFC} /$ $\mathrm{mL}$, Enterobacteriaceae 4,76 x $10^{4} \mathrm{UFC} / \mathrm{mL}$ y Staphylococcus 1,42 x $10^{4} \mathrm{UFC} / \mathrm{mL}$. Se pudo detectar en dos de las muestras la presencia de Salmonella. Los resultados obtenidos en este estudio indican que se está en presencia de leche cruda con valores muy altos de los indicadores bacteriológicos, lo cual implica deficiencias en su calidad sanitaria, sobre todo en la época de invierno.

Palabras clave: leche cruda bovina, calidad bacteriológica, centro de acopio

\begin{abstract}
Bacteriological quality of bovine raw milk has very important economic and health implications for the agricultural development worldwide. In this context, the present study was carried out to document
\end{abstract}


the bacteriological quality of bovine raw milk stored in a collection center in the province of Tungurahua, Ecuador. A total of 20 milk samples obtained during the rainy and the dry season from the storage tanks of the transport routes together with samples from the collection center were analyzed. The following indicator of bacteriological quality were quantified: mesophilic aerobic bacteria, Enterobacteriaceae, Staphylococcus and Salmonella. These indicators adjust to the Ecuadorian INEN standards for bovine raw milk, which were quantified using the culture media and the incubation conditions indicated in the standards for each of the bacterial groups evaluated. In the rainy season average values for mesophilic aerobic bacteria were $1.22 \times 10^{8} \mathrm{CFU} / \mathrm{mL}$, Enterobacteriaceae $7.90 \times 10^{5} \mathrm{CFU} / \mathrm{mL}$ and Staphylococcus $6.12 \times 10^{4} \mathrm{CFU} / \mathrm{mL}$. In the dry season average values of mesophilic aerobic bacteria were 8.07 x $10^{6} \mathrm{CFU} / \mathrm{mL}$, Enterobacteriaceae $4.76 \times 10^{4} \mathrm{CFU} / \mathrm{mL}$ and Staphylococcus $1.42 \times 10^{4} \mathrm{CFU} / \mathrm{mL}$. Salmonella was detected in 2 samples. Results of this study show that the bacteriological indicators of raw milk are high, implying deficiencies in the raw milk sanitary quality, especially during the rainy season.

Keywords: raw bovine milk, bacteriological quality, collection center.

\section{Introducción}

La microbiota que se encuentra en la leche cruda bovina incluye microorganismos que están presentes en la ubre y piel de la vaca, así como de aquellos provenientes del medio ambiente que se van agregando al producto durante los procesos de ordeño, manipulación, tratamiento y almacenamiento. La variación en la composición taxonómica de esta comunidad microbiana se ha visto que se asocia a diferencias en las prácticas de manipulación y producción lechera implementadas en cada factoría (Fischer et al., 2011; Lan et al., 2017).

Se han realizado numerosos estudios sobre la microbiota bacteriana presente en la leche, los cuales han permitido conocer que la porción más abundante de esta compleja comunidad la constituyen las bacterias heterótrofas, que incluyen la mayoría de las bacterias patógenas causantes de diversos tipos de infecciones en el rebaño vacuno. De igual forma, dentro de la microbiota de la leche existe una porción de microorganismos que han demostrado tener beneficios para la salud de los consumidores (probióticos) que, además, se han utilizado a nivel de la industria láctea por su capacidad de descomponer diversos tipos de sustancias orgánicas, y también porque están involucradas en una amplia variedad de procesos fundamentales en la transformación industrial de la leche (Guarín Patarroyo y Restrepo Ochoa, 2020; Pal et al., 2016; Reuben et al., 2020).

La composición estructural y funcional de las comunidades bacterianas es el principal índice del estado de los ecosistemas y, entendiendo la leche bovina como un ecosistema muy particular, se debe estudiar la diversidad de su microbiota para poder conocer el grado de contaminación, las fuentes y calidad de alimentación de los rebaños, el estado fisiológico y de salud de los animales productores, así como su procedencia geográfica. Dependiendo de estos conocimientos podremos destinar la leche para su consumo o utilizarla en algún proceso tecnológico que resulte en la producción de derivados lácteos (Doyle et al., 2017; Lan et al., 2017).

Existen diversos factores que influyen sobre la calidad bacteriológica de la leche, estos factores pueden ser de tipo ambiental, fisiológico o genético. Dentro de lo ambiental se reconoce la alimentación del animal, la época del año y las temperaturas; en lo fisiológico se consideran el ciclo de lactancia, enfermedades, entre ellas la mastitis, y los hábitos de ordeño; en cuanto a los factores genéticos se destacan la raza y las características individuales del animal (Derakhshani et al., 2018).

En Ecuador, los estudios sobre la microbiología de la leche cruda bovina se han enfocado principalmente en la evaluación de los indicadores de calidad sanitaria, la búsqueda de ciertas bacterias patógenas, así como la evaluación de los aspectos relacionados con las regulaciones sanitarias y económicas (Arguelles et al., 2015; Chuquín Yépez et al., 2016; Chimborazo Ashqui, 2020; Contero et al., 2021; Guevara-Freire et al., 2019; Ramírez Robles y Lluman Marcatoma, 2020; Requelme y Bonifaz, 2012).

Conocer la calidad bacteriológica de la leche es muy importante desde el punto de vista de la salud pública; en la leche podemos conseguir una gran diversidad de bacterias que pueden causar diferentes tipos de infecciones e intoxicaciones en los humanos y que se pueden transmitir a través del consumo de leche cruda no pasteurizada o de sus productos derivados, tales como las cremas de leche, helados y quesos (Andueza-Leal, 2005; Lucey, 2015; Albuja Landi et al., 2018; Artursson et al., 2018; Guarín Patarroyo y Restrepo Ochoa, 2020).

Por otra parte, la calidad sanitaria de la leche tiene una importancia económica ya que es uno de los factores a considerar en el establecimiento del precio de la leche en el ámbito de los productores, así como en los precios de los derivados lácteos obtenidos (Contero et al., 2021; Acuerdo N³94; Requelme y Bonifaz, 2012). 
No existen estudios publicados sobre la calidad bacteriológica de la leche cruda bovina de fincas ubicadas en la provincia de Tungurahua que sean almacenadas en el centro de acopio del cantón Mocha. En este sentido, el presente trabajo pretende establecer la calidad bacteriológica de la leche en esta zona del país, lo cual es muy importante desde un punto de vista sanitario y de salud pública, así como al momento de querer establecer denominaciones de origen en los productos lácteos que se producen en las diversas zonas de la provincia de Tungurahua.

\section{Materiales y métodos}

\subsection{Selección de la muestra}

Las muestras de leche se recolectaron tanto del tanque del centro de acopio, ubicado en el cantón Mocha, perteneciente a la provincia de Tungurahua, Ecuador (Figura 1), con una latitud de $1^{\circ} 25^{\prime} 10.3^{\prime \prime} \mathrm{S}$ y una longitud de $78^{\circ} 39^{\prime} 12.5^{\prime} \mathrm{W}$, donde se almacenan aproximadamente 2.000 litros de leche diariamente, así como de los tanques de los transportes que recolectan la leche en las cuatro rutas de abastecimiento ( 91 proveedores entre fincas del sector, pequeños, medianos y grandes ganaderos). La composición en el número de productores y volumen promedio de leche recolectada en cada una de las rutas fue:

- $\quad$ Ruta 1: 31 productores (843 litros por día)

- $\quad$ Ruta 2: 18 productores (325 litros por día)

- $\quad$ Ruta 3: 23 productores (430 litros por día)

- $\quad$ Ruta 4: 19 productores (396 litros por día)

Los muestreos se realizaron en dos épocas diferentes del año, fundamentándose en el hecho de que existen trabajos previos que indican que las condiciones climáticas y ambientales influyen en el crecimiento microbiano. Las muestras se tomaron en los meses de la época de seca o verano y en los meses de la época lluviosa o invierno, de acuerdo con los datos de pluviosidad de la zona (verano: septiembre 2019 y agosto 2020; invierno: diciembre 2019 y enero 2021), siguiendo para ello los criterios indicados por la norma ecuatoriana para la recolección de muestras de leche cruda y manteniendo durante todo el proceso las medidas de higiene y asepsia adecuadas (NTE INEN 1529-2:2013).

Las muestras de un volumen de $250 \mathrm{~mL}$ de leche se recolectaron por duplicado, asépticamente, a través de la llave, previamente desinfectada con alcohol, de cada uno de los tanques de almacenamiento de los camiones de transporte de cada ruta de distribución. De igual manera, se tomaron muestras del tanque central de almacenamiento del centro de acopio, recabando un total de 10 muestras por cada muestreo, para un total de 20 muestras.

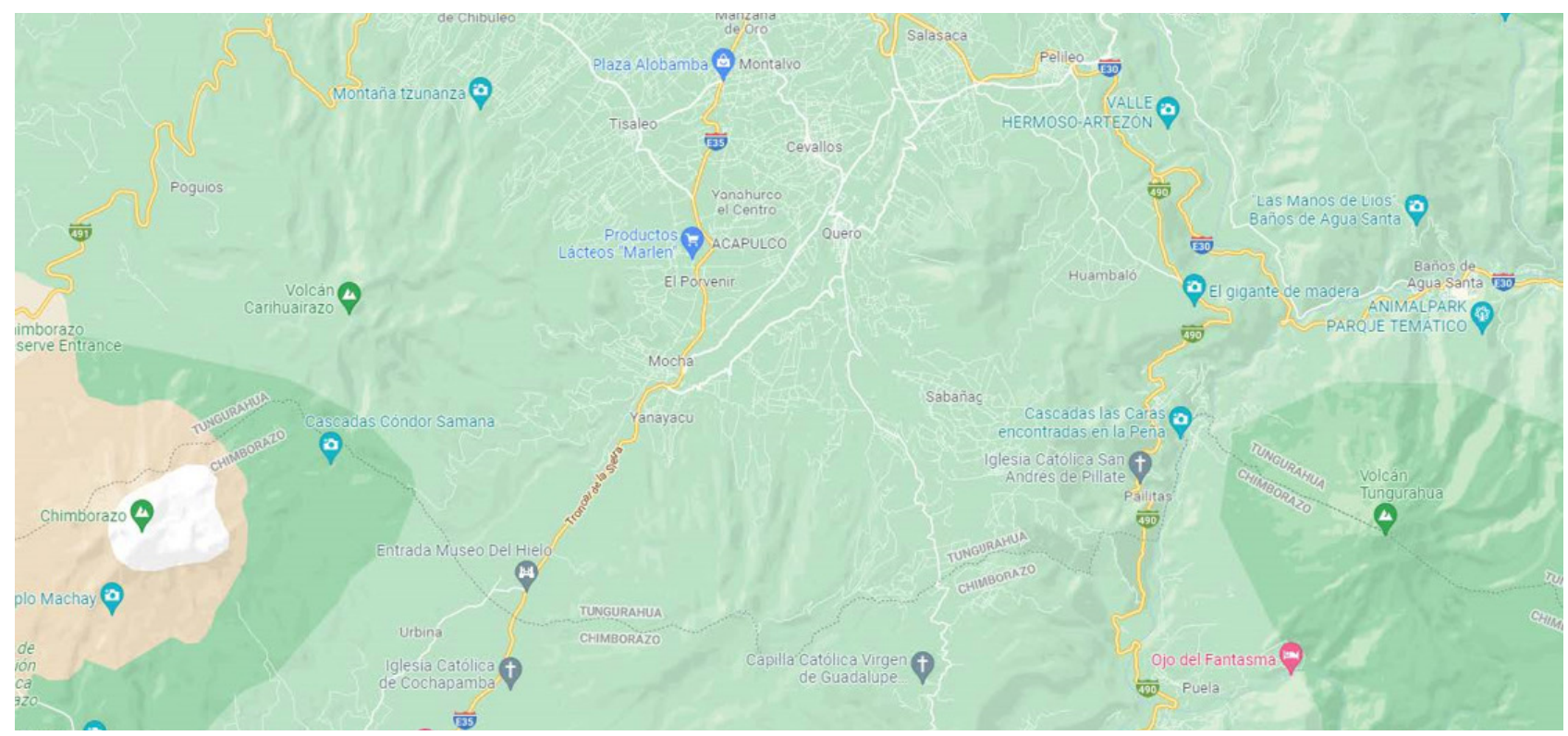

Figura 1. Mapa de ubicación del cantón Mocha (https://www.google.com/maps/place/Cantón Mocha).

Figure 1. Location map of Mocha Minicipality (https://www.google.com/maps/place/Cantón Mocha). 


\subsection{Manejo de las muestras}

Se consideró lo determinado en la Norma Ecuatoriana NTE INEN 1529-2:2013, que establece las directrices para el muestreo destinado a los análisis microbiológicos, selección de los envases para la recolección de las muestras, esterilización del material de vidrio y utensilios empleados, tratamiento, conservación y transporte refrigerado de las muestras hasta el laboratorio.

\subsection{Identificación y preparación de las muestras para el análisis microbiológico}

Se siguió el procedimiento indicado en la Norma Ecuatoriana NTE INEN 1529-2:2013, que contempla el manejo aséptico y seguro de las muestras. De igual forma, a cada una de las muestras de leche se les realizaron diluciones decimales seriadas en agua peptonada al 0,1\%. Para la preparación de las diluciones se siguió lo especificado en la Norma NTE INEN 1529-2:2013.

\subsection{Cuantificación de la microbiota bacteriana}

\subsubsection{Cuantificación de la cantidad de bacterias aerobias mesófilas}

Para determinar el número de bacterias aerobias mesófilas presente en las muestras de leche, se utilizó el método de siembra por profundidad utilizando agar plate count. Se inocularon placas por duplicado con $1 \mathrm{~mL}$ de cada una de las muestras y de sus diluciones $10^{-4}, 10^{-5}$ y $10^{-6}$. Las placas se incubaron a una temperatura de 30 ${ }^{\circ} \mathrm{C} \pm 2^{\circ}$, por un período de 2 a 5 días. Finalizado el tiempo de incubación se realizaron los cálculos correspondientes para expresar los resultados de los contajes en placas de Petri, como unidades formadoras de colonia por mililitro de leche (UFC/mL). Todo se realizó según lo estipulado en la Norma Ecuatoriana NTE INEN 1529-5:2006.

\subsubsection{Enumeración de la cantidad de bacterias del grupo de las Enterobacteriaceae}

En la valoración de la cantidad de bacterias del grupo de las Enterobacteriaceae presente en las muestras de leche estudiadas, se utilizó el método de siembra por profundidad utilizando agar MacConkey. Se inocularon placas por duplicado con $1 \mathrm{~mL}$ de cada una de las muestras y de sus diluciones $10^{-4}, 10^{-5}$ y $10^{-6}$. Las placas se incubaron a una temperatura de $37^{\circ} \mathrm{C} \pm 2^{\circ}$, por un período de 2 días. Finalizado el tiempo de incubación se realizaron los cálculos correspondientes para expresar los resultados de los contajes en placas de Petri como UFC/mL. Todo se realizó de acuerdo con la Norma Ecuatoriana NTE INEN 1529-13:98.

\subsubsection{Recuento de bacterias del género Staphylococcus spp.}

Para determinar el número de bacterias del género Staphylococcus presente en las muestras de leche recolectadas, tanto de los tanques de almacenamiento de los camiones de transporte, como del tanque de almacenamiento central del centro de acopio, se utilizó el método de siembra por extensión utilizando agar Baird Parker. Se inocularon placas por duplicado con $0,1 \mathrm{~mL}$ de cada una de las muestras y de sus diluciones $10^{-4}, 10^{-5} \mathrm{y} 10^{-6}$. Las placas se incubaron a una temperatura de $37^{\circ} \mathrm{C} \pm 2^{\circ}$, por un período de 2 días. Finalizado el tiempo de incubación se realizaron los cálculos correspondientes para expresar los resultados de los contajes en placas como UFC/mL. Los análisis se realizaron de acuerdo con lo señalado en la Norma Ecuatoriana NTE INEN 1529-14.

\subsubsection{Detección de la presencia de células de Salmonella spp.}

Para determinar la presencia de bacterias del género Salmonella en las muestras de leche investigadas, se utilizó el método de enriquecimiento selectivo, colocando $90 \mathrm{~mL}$ de cada una de las muestras sin diluir en $900 \mathrm{~mL}$ de caldo selenito y $900 \mathrm{~mL}$ de caldo tetrationato, los cuales se incubaron simultáneamente a una temperatura de $37^{\circ} \mathrm{C} \pm 2^{\circ}$, durante un tiempo de 12 horas. Finalizado el tiempo de incubación se sembraron por la técnica de extensión, $0,1 \mathrm{~mL}$ de cada uno de los caldos de enriquecimiento, en cajas de Petri contentivas de los medios de cultivos Salmonella-Shigella y Bismuto sulfito, incubándose posteriormente a una temperatura de $37^{\circ} \mathrm{C} \pm$ $2^{\circ}$, durante 48 horas. Finalizado el tiempo de incubación se expresaron los resultados como ausente o presentes 
Los análisis y su interpretación se realizaron según lo indicado en la Norma Ecuatoriana NTE INEN 1529-15.

\subsection{Análisis estadístico de los resultados}

Para cada grupo de datos obtenidos en la valoración de los parámetros estudiados se determinó la media y desviación estándar, utilizando el programa estadístico SPSS (IBM SPSS Statistics 27.0.1). Se utilizó el análisis estadístico descriptivo para estudiar las diferencias en los parámetros evaluados en las dos épocas del año. Se empleó la prueba t para medias de dos muestras emparejadas y el valor de significancia $p$, mediante el programa SPSS (IBM SPSS Statistics 27.0.1).

\section{Resultados y Discusión}

\subsection{Recuento de bacterias aerobias mesófilas}

Los microrganismos indicadores de calidad higiénica de la leche se definen como grupos microbianos que cuando están presentes en altas concentraciones señalan una deficiente aplicación de las prácticas de higiene y limpieza, sobre todo durante los procesos de obtención (ordeño), almacenamiento (centro de acopio) o procesamiento (industria) de la leche, siendo los más utilizados el de las bacterias aerobias mesófilas, coliformes totales y el de las enterobacterias (Quigley, 2013).

Los microorganismos mesófilos poseen una temperatura óptima de crecimiento que oscila entre $25^{\circ} \mathrm{C}$ y $40{ }^{\circ} \mathrm{C}$, la cual es también propicia para el desarrollo de las principales bacterias patógenas (Mallet et al., 2012).

En la Tabla 1 se muestran los resultados en los recuentos de aerobios mesófilos en muestras de leche proveniente de los tanques en los transportes de cada una de las rutas estudiadas, así como del tanque de almacenamiento del centro de acopio de Mocha. Al analizar los datos de dicha tabla, se observa que se obtuvo un valor promedio de bacterias aerobios mesófilos de $1,22 \times 10^{8} \mathrm{UFC} / \mathrm{mL}$ en la época de invierno y 8,07 × $10^{6}$ $\mathrm{UFC} / \mathrm{mL}$ en la época de verano, siendo estadísticamente diferentes los recuentos en las dos épocas evaluadas ya que se obtuvo un valor de $p$ de $0,0047(p<0,05)$.

En un estudio similar realizado en Colombia, los autores exponen que existen diferencias en los recuentos de bacterias aerobias obtenidos en diferentes estaciones climáticas. En época de lluvia, de acuerdo con los autores, hay mayor exposición del ganado al estiércol y la tierra, por lo que los recuentos de aerobios mesófilos aumentan (Moreno Vásquez et al., 2007).

Por otra parte, de acuerdo con la investigación realizada por Godic-Torkar y Golc-Tejer (2008), durante la época de lluvia las condiciones de temperatura y concentración de oxígeno disuelto cambian en la leche, favoreciendo el crecimiento de la microbiota psicotrofa y psicrófila aerobia, que en algunos casos llega a representar entre el 10 al $50 \%$ de la microbiota total de los recuentos de aerobios mesófilos (Bramley, 1990; Villar et al., 1996), lo que se traduce en una aumento de los valores de estos recuentos en esta estación climática.

Las bacterias mesófilas son consideradas como indicadores de higiene, sin embargo, su presencia en la leche es inevitable ya que la mayoría de estos géneros están presentes en la ubre del animal, las manos de los ordeñadores, las superficies del equipo, en el agua y en el aire. Por lo tanto, los altos recuentos de mesófilos están directamente influenciados por las condiciones en las que la leche se somete después del ordeño, sobre todo la temperatura de almacenamiento (Giacometti et al., 2012; Kim et al., 2017).

Según la normativa ecuatoriana NTE INEN 9:2012, el límite permisible para el recuento de bacterias aerobias mesófilas es de $1,51 \times 10^{6} \mathrm{UFC} / \mathrm{mL}$, comparando este valor con los datos obtenidos en el estudio, se encuentra que en ninguna de las muestras, tanto las obtenidas en la época de verano como la obtenida en la época de invierno, cumplen con los valores límites permitidos en la normativa ecuatoriana, señalando de esta manera que la leche procedente del centro de acopio de Mocha no tendría una buena calidad bacteriana.

De igual forma, si se compara los valores obtenidos en los recuentos de bacterias aerobias mesófilas en los diferentes muestreos con los valores de referencia establecidos en el Acuerdo $\mathrm{N}^{\circ} 394$ para el pago de incentivos por la calidad sanitaria de la leche, se encuentra que los valores observados en la investigación son mucho mayores, indicando una leche de una deficiente calidad sanitaria.

Nero y De Carvalho (2018) señalan que la leche con recuentos de bacterias mesófilas superiores a 1,00 x $10^{5} \mathrm{UFC} / \mathrm{mL}$, indica una mala calidad higiénica durante el ordeño y la producción, mientras que los recuentos inferiores a $1,00 \times 10^{3} \mathrm{UFC} / \mathrm{mL}$ reflejan unas buenas prácticas de producción y manipulación del producto. 
Los altos recuentos de aerobios mesófilos observados en este estudio son similares a los encontrados por Guevara-Freire et al. (2019) en pequeñas ganaderías de la provincia de Cotopaxi en Ecuador, con rango en los valores del recuento entre 7,76 × $10^{7}$ a 7,90 x $10^{7} \mathrm{UFC} / \mathrm{mL}$. Los autores del trabajo asocian los valores observados a las inadecuadas prácticas de ordeño utilizadas por los productores de la zona, el uso compartido de toallas no desechables, la utilización del ternero en la estimulación de la glándula mamaria, la no higienización de las ubres, utensilios con impurezas y tanques sucios, situaciones que podrían estar también presentes en las zonas de donde provienen las leches evaluadas en la presente investigación.

En un estudio de la leche cruda bovina realizado en Noruega por Skeie et al. (2019) se indican recuentos de mesófilos entre $3,98 \times 10^{3}$ y $1,91 \times 10^{5} \mathrm{UFC} / \mathrm{mL}$, encontrando diferencias significativas entre dos áreas geográficas, datos muy por debajo de los recuentos obtenidos en la presente investigación, aunque presentan coincidencias en las diferencias observadas de los contajes entre las épocas de verano e invierno.+

Li et al. (2018) analizan la variación en la microbiota de la leche cruda bovina en algunas regiones de China a lo largo de 12 meses y el impacto de las condiciones climáticas sobre ellas, concluyendo que la temperatura y la humedad son los factores determinantes en la variación en el número y composición de la población bacteriana. Los autores señalan que la riqueza bacteriana es generalmente baja en invierno y alta en verano, lo cual se contrapone a las variaciones encontradas en el presente trabajo, ello debido muy probablemente a las condiciones climáticas y geográfica de Ecuador (zona andina), donde se tiene una temperatura media entre 12-16 ${ }^{\circ} \mathrm{C}$ a lo largo de todo año, con una fluctuación de $\pm 2,2{ }^{\circ} \mathrm{C}$ y lo que marca la diferencia entre invierno y verano es la presencia de lluvia (Portilla Farfán, 2018), misma que es considerablemente abundante en invierno lo que favorecería, en el país, a una mayor contaminación del ganado con estiércol y tierra incrementando de esta manera los niveles de aerobios mesófilos en la leche.

Por otra parte, se debe considerar la variación en factores como el manejo de la finca, las condiciones climáticas y las prácticas de saneamiento, similar a lo indicado por Porcellato et al. (2018) en un estudio realizado en Noruega.

Tabla 1. Resultados del recuento promedio de microorganismos aerobios mesófilos. Muestreos en época de invierno y de verano. Centro de acopio Mocha, Tungurahua. Ecuador.

Table 1. Results of the average count of mesophilic aerobic microorganisms. Samplings in rainy and dry seasons. Mocha collection center. Tungurahua. Ecuador.

\begin{tabular}{|c|c|c|c|c|}
\hline & \multicolumn{2}{|c|}{ Invierno (lluvioso) } & \multicolumn{2}{|c|}{ Verano (seco) } \\
\hline & Muestreo 1 & Muestreo 2 & Muestreo 1 & Muestreo 2 \\
\hline & (UFC/mL) & (UFC/mL) & (UFC/mL) & (UFC/mL) \\
\hline Ruta 1 & $2,8 \times 10^{7} \pm 5,8$ & $14,5 \times 10^{7} \pm 5,8$ & $4,1 \times 10^{6} \pm 0,6$ & $2,82 \times 10^{6} \pm 0,6$ \\
\hline Ruta 2 & $19,1 \times 10^{7} \pm 8,9$ & $1,4 \times 10^{7} \pm 8,9$ & $11,2 \times 10^{6} \pm 4,6$ & $2,0 \times 10^{6} \pm 4,6$ \\
\hline Ruta 3 & $25,7 \times 10^{7} \pm 10,5$ & $4,79 \times 10^{7} \pm 10,5$ & $2,3 \times 10^{6} \pm 4,9$ & $12,0 \times 10^{6} \pm 4.9$ \\
\hline Ruta 4 & $3,0 \times 10^{7} \pm 9,7$ & $22,4 \times 10^{7} \pm 9,7$ & $21,4 \times 10^{6} \pm 9,8$ & $1,8 \times 10^{6} \pm 9,8$ \\
\hline Tanque & $26,9 \times 10^{7} \pm 12,6$ & $1,7 \times 10^{7} \pm 12,6$ & $3,0 \times 10^{6} \pm 8,5$ & $20,0 \times 10^{6} \pm 8,5$ \\
\hline Media & \multicolumn{2}{|c|}{$1,22 \times 10^{8}$} & \multicolumn{2}{|c|}{$8,07 \times 10^{6}$} \\
\hline Estadístico $t$ & \multicolumn{4}{|c|}{3,283} \\
\hline$p$ & \multicolumn{4}{|c|}{0,0095} \\
\hline
\end{tabular}

Nota: UFC/mL: Unidades formadoras de colonias por mililitro; $t$ : $t$ de Student; $p$ : nivel de significancia estadística.

\subsection{Recuento de Enterobacteriaceae}

Las Enterobacteriaceae son un grupo de bacterias Gram negativas que incluyen a los coliformes, tienen la capacidad de fermentar o no la lactosa y producir gas. Cuando estos microorganismos están presentes en recuentos superiores a $100 \mathrm{UFC} / \mathrm{mL}$ (Nero y De Carvalho, 2018) evidencian prácticas de higiene deficientes en el procesamiento de la leche, principalmente durante el ordeño (métodos de limpieza de los pezones). Además de señalar la posible presencia de enteropatógenos los recuentos de las Enterobacteriaceae se pueden utilizar como un indicador de la contaminación bacteriana que ha ocurrido durante los distintos pasos de la cadena de obtención de la leche cruda (Ntuli et al., 2016; Pyz-Łukasik et al., 2015). 
Dada la utilidad de las Enterobacteriaceae para evidenciar las buenas prácticas de higiene en la obtención de la leche, se incluyó su determinación en el presente estudio, aunque en las normas ecuatorianas sobre la leche cruda no se considera su evaluación.

Los datos obtenidos en los recuentos de Enterobacteriaceae se presentan en la Tabla 2. Al analizar los valores obtenidos se puede indicar un valor promedio de $7,90 \times 10^{5} \mathrm{UFC} / \mathrm{mL}$ en época de invierno, diferenciándose significativamente con un valor de $p$ de $0,037(p<0.05)$ respecto a los recuentos obtenidos durante el verano, en donde se obtienen valores de 4,76 × $10^{4} \mathrm{UFC} / \mathrm{mL}$, coincidiendo en este aspecto con lo señalado en el estudio de Mallet et al. (2012), donde se correlacionaron los recuentos de bacterias Gram negativas con la temporada de ordeño, siendo la época de lluvia la de mayor influencia en la carga microbiana, principalmente de la bacteria Escherichia coli cuyo hábitat son las heces fecales de humanos y animales (Lan et al., 2017; Skeie et al., 2019).

Por otro lado, de acuerdo con los resultados obtenidos por Kim et al. (2017) en un estudio realizado en Corea del Sur, las diferencias en los contajes serían causadas por entornos regionales agrícolas diferentes, tales como el suelo, el forraje y el equipo de producción lechera.

Los resultados observados para las Enterobacteriaceae en invierno son similares en magnitud a los obtenidos por Millán et al. (2018) en un estudio realizado en Mérida Venezuela, donde se obtienen valores promedios de 1,4 x $10^{5} \mathrm{UFC} / \mathrm{mL}$ de Enterobacteriaceae en muestras de leches de esa zona. Los autores señalan que los resultados observados indicarían una leche de mala calidad sanitaria y que no podría ser consumida sin tener previamente un procesamiento térmico adecuado.

Tabla 2. Recuento promedio de Enterobacteriaceae. Muestreo en época de invierno y verano. Centro de acopio Mocha, Tungurahua, Ecuador

Table 2. Average count of Enterobacteriaceae. Sampling in rainy and dry seasons. Mocha collection center. Tungurahua. Ecuador.

\begin{tabular}{|c|c|c|c|c|}
\hline & \multicolumn{2}{|c|}{ Invierno (lluvioso) } & \multicolumn{2}{|c|}{ Verano (seco) } \\
\hline & Muestreo 1 & Muestreo 2 & Muestreo 1 & Muestreo 2 \\
\hline & (UFC/mL) & (UFC/mL) & (UFC/mL) & (UFC/mL) \\
\hline Ruta 1 & $2,69 \times 10^{5} \pm 10,4$ & $23,40 \times 10^{5} \pm 10,4$ & $2,04 \times 10^{4} \pm 5,3$ & $12,6 \times 10^{4} \pm 5,3$ \\
\hline Ruta 2 & $2,82 \times 10^{5} \pm 0,2$ & $2,40 \times 10^{5} \pm 0,2$ & $8,71 \times 10^{4} \pm 2,5$ & $3,63 \times 10^{4} \pm 2,5$ \\
\hline Ruta 3 & $3,02 \times 10^{5} \pm 0,6$ & $1,74 \times 10^{5} \pm 0,6$ & $2,57 \times 10^{4} \pm 0,5$ & $3,55 \times 10^{4} \pm 0,5$ \\
\hline Ruta 4 & $1,62 \times 10^{5} \pm 5,3$ & $12,30 \times 10^{5} \pm 5,3$ & $9,12 \times 10^{4} \pm 3,9$ & $1,23 \times 10^{4} \pm 3,9$ \\
\hline Tanque & $26,9 \times 10^{5} \pm 12,4$ & $2,09 \times 10^{5} \pm 12,4$ & $2,88 \times 10^{4} \pm 0,8$ & $1,23 \times 10^{4} \pm 0,8$ \\
\hline Media & \multicolumn{2}{|c|}{$7,90 \times 10^{5}$} & \multicolumn{2}{|c|}{$4,76 \times 10^{4}$} \\
\hline Estadístico $t$ & \multicolumn{4}{|c|}{2,452} \\
\hline$p$ & \multicolumn{4}{|c|}{0,037} \\
\hline
\end{tabular}

Nota: UFC/mL: Unidades formadoras de colonias por mililitro; $t$ : $\mathrm{t}$ de Student; $p$ : nivel de significancia estadística.

\subsection{Recuento de Staphylococcus aureus}

Se ha observado en el presente estudio una alta prevalencia de bacterias del género, Staphylococcus con recuentos elevados en el 100\% de las muestras analizadas (Tabla 3 ), con valores que van desde $6,12 \times 10^{4} \mathrm{UFC} /$ $\mathrm{mL}$ en invierno a $1,42 \times 10^{4} \mathrm{UFC} / \mathrm{mL}$ en verano, obteniéndose una $p$ de 0,043 , lo cual indica una diferencia estadísticamente significativa $(p<0.05)$ entre los recuentos de las dos épocas climáticas evaluadas.

Los resultados observados en cuanto a la prevalencia del género Staphylococcus en las muestras de leches crudas son similares a los indicados por autores de diversas partes del mundo que han podido aislar cepas del género Staphylococcus a partir de muestras de leches obtenidas de tanques de almacenamiento (Haran et al., 2012; Jayaro y Henning, 2001; Neder et al., 2011).

Investigadores como Pacha et al. (2021) han indicado que la presencia de cepas de Staphylococcus en la leche cruda de los tanques de almacenamiento pueden provenir de los recipientes utilizados en las fincas, en donde, si no se realiza una buena desinfección de éstos, esta bacteria puede formar biofilm y serviría como un reservorio de células que, al pasar la leche recién ordeñada, podría arrastrar parte de la comunidad bacteriana del biofilm, incluido los Staphylococcus. 
Especies del género Staphylococcus se les ha asociado con las infecciones de mastitis bovina encontrándose en algunos estudios inclusive en la piel de pezón y en los equipos empleados para el ordeño (Neviani et al., 2013; Oikonomou et al., 2020; Skeie et al., 2019).

El modo de transmisión de la mastitis se ha indicado puede ser contagioso o ambiental. Existen numerosos agentes etiológicos que son responsables de esta enfermedad, sin embargo, la mayoría de las mastitis son causadas por bacterias de los géneros Staphylococcus, Streptococcus y del grupo Enterobacteriaceae, grupos bacterianos encontrados en el presente estudio, coincidiendo en este aspecto con el trabajo realizado por Porcellato et al. (2018).

Por otro lado, una fuente importante de patógenos que causan mastitis se encuentra también en el ambiente que rodea al animal, como es el caso de las bacterias del grupo de las Enterobacteriaceae (Bonizzi et al., 2009; Nero y De Carvalho, 2018; Jiménez Velásquez et al., 2020), encontradas de igual forma en la presente investigación.

Hoque et al. (2019), señalan que la infección en los animales generalmente ocurre cuando las bacterias ingresan a la glándula mamaria, principalmente por la ruptura de las barreras físicas de los cuartos mamarios, lo que requiere defensas oportunas y adecuadas del huésped para prevenir la colonización y la patología de la enfermedad y de allí pasaría a la leche.

Los resultados obtenidos son diferentes a los observados en un estudio realizado en China donde solo se pudo detectar la presencia de Staphylococcus en el 52,50\% de las muestras evaluadas, además de que los recuentos en invierno fueron significativamente menores a los de verano (Lan et al., 2017).

En otro estudio sobre la microbiología de la leche cruda realizado en Suecia los resultados revelan una alta prevalencia de Staphylococcus aureus, similar al obtenido en la presente investigación (Artursson, 2018).

Los recuentos de Staphylococcus aureus en las dos épocas del año evidencian variaciones que podrían ser el resultado de factores tales como cambios en la calidad del alimento, el entorno de la granja, el clima, prácticas de ordeño y condiciones sanitarias y de la salud de los animales (Oikonomou et al., 2020; Quigley et al., 2013).

Diversos investigadores han señalado que Staphylococcus aureus puede contaminar la leche cruda durante el contacto con los recipientes y utensilios empleados en el ordeño y manipulación de la leche, así como por su transmisión a partir de la nariz, ojos, cabello, garganta y manos de ordeñadores portadores de esta bacteria (Fischer et al., 2011; Fusco et al., 2020; Quigley et al., 2013; Skeie et al., 2019).

Tabla 3. Recuento promedio de Staphylococcus aureus en época de invierno y verano. Centro de acopio Mocha, Tungurahua, Ecuador. Table 3. Average count of Staphylococcus aureus in rainy and dry seasons. Mocha collection center. Tungurahua. Ecuador.

\begin{tabular}{|c|c|c|c|c|}
\hline & \multicolumn{2}{|c|}{ Invierno (Iluvioso) } & \multicolumn{2}{|c|}{ Verano (seco) } \\
\hline & $\begin{array}{c}\text { Muestreo } 1 \\
\text { (UFC/mL) }\end{array}$ & $\begin{array}{c}\text { Muestreo } 2 \\
\text { (UFC/mL) }\end{array}$ & $\begin{array}{c}\text { Muestreo } 1 \\
\text { (UFC/mL) }\end{array}$ & $\begin{array}{c}\text { Muestreo } 2 \\
(\mathrm{UFC} / \mathrm{mL})\end{array}$ \\
\hline Ruta 1 & $17,0 \times 10^{4} \pm 7,4$ & $2,29 \times 10^{4} \pm 7,4$ & $0,94 \times 10^{4} \pm 0,6$ & $2,07 \times 10^{4} \pm 0,6$ \\
\hline Ruta 2 & $1,93 \times 10^{4} \pm 7,5$ & $17,0 \times 10^{4} \pm 7,5$ & $1,26 \times 10^{4} \pm 0,2$ & $1,68 \times 10^{4} \pm 0,2$ \\
\hline Ruta 3 & $3,05 \times 10^{4} \pm 3,5$ & $10,0 \times 10^{4} \pm 3,5$ & $1,29 \times 10^{4} \pm 0,1$ & $1,07 \times 10^{4} \pm 0,1$ \\
\hline Ruta 4 & $3,24 \times 10^{4} \pm 0,2$ & $2,88 \times 10^{4} \pm 0,2$ & $1,40 \times 10^{4} \pm 0,1$ & $1,17 \times 10^{4} \pm 0,1$ \\
\hline Tanque & $2,07 \times 10^{4} \pm 0,1$ & $1,80 \times 10^{4} \pm 0,1$ & $1,15 \times 10^{4} \pm 0,5$ & $2,14 \times 10^{4} \pm 0,5$ \\
\hline Media & \multicolumn{2}{|c|}{$6,12 \times 10^{4}$} & \multicolumn{2}{|c|}{$1,42 \times 10^{4}$} \\
\hline Estadístico $t$ & \multicolumn{4}{|c|}{2,351} \\
\hline$p$ & \multicolumn{4}{|c|}{0,043} \\
\hline
\end{tabular}

Nota: UFC/mL: Unidades formadoras de colonias por mililitro; $t$ : $\mathrm{t}$ de Student; $p$ : nivel de significancia estadística.

\subsection{Determinación de la presencia de Salmonella spp.}

Salmonella es una bacteria enteropatógena que puede ser transmitida a la leche cruda desde diversas fuentes, si bien la bibliografía la ubica como uno de los principales agentes de enfermedades transmitidas por los ali- 
mentos (ETAS), la pasteurización adecuada las inactiva. Brotes de salmonelosis relacionados con productos lácteos han involucrado principalmente la leche cruda y los quesos frescos obtenidos de leche cruda (Fusco et al., 2020; Nero y De Carvalho, 2018). En el presente estudio se determinó la presencia de Salmonella en el $10 \%$ de las muestras estudiadas (Tabla 4).

La prevalencia de Salmonella observada en la leche almacenada en el centro de acopio de Mocha es mayor a la encontrada en estudios realizados en China (2,9\%), Malasia (1,4\%), Estados Unidos $(2,6 \%)$, Nueva Zelanda (0\%) e Italia (0,3\%) (Lan et al., 2017; Li et al., 2018), países que se caracterizan por contar con estrictos controles de calidad de la leche cruda, minimizando la presencia de patógenos oportunistas mediante el control de la salud animal, condiciones de ordeño y el almacenamiento, garantizando de esta manera la inocuidad de la materia prima a la industria lechera.

Ecuador ha venido trabajando, a través de sus entidades estatales de control fitosanitario en la implementación de acciones para mejorar la calidad de la leche cruda, mediante la certificación de buenas prácticas pecuarias en producción de leche, sin embargo, aún prevalecen las condiciones que hacen propicio el crecimiento de bacterias, entre ellas las patógenas, en la leche producida en las diferentes regiones del país (Nogales y Granada, 2012).

$$
\begin{aligned}
& \text { Tabla 4. Determinación cualitativa de Salmonella en época de invierno y verano. Cen- } \\
& \text { tro de acopio Mocha, Tungurahua, Ecuador. } \\
& \text { Table 4. Qualitative determination of Salmonella in rainy and dry seasons. Mocha } \\
& \text { collection center. Tungurahua. Ecuador. }
\end{aligned}
$$

\begin{tabular}{cccccc}
\hline & \multicolumn{2}{c}{ Invierno (lluvioso) } & & \multicolumn{2}{c}{ Verano (seco) } \\
\cline { 2 - 3 } \cline { 5 - 6 } Ruta 1 & Muestreo 1 & Muestreo 2 & & Muestreo 1 & Muestreo 2 \\
Ruta 2 & Presencia & Ausencia & & Ausencia & Ausencia \\
Ruta 3 & Ausencia & Ausencia & & Ausencia & Ausencia \\
Ruta 4 & Ausencia & Ausencia & & Ausencia & Ausencia \\
Tanque & Ausencia & & Ausencia & Presencia \\
\hline
\end{tabular}

Dentro de los factores relevantes que afectan también la composición de la microbiota de la leche cruda se encuentran el tipo de forraje (pasto, ensilado y heno) con el cual se alimenta a los animales, las condiciones higiénicas de los animales y las condiciones de almacenamiento de la leche (Kuhn et al., 2018; Lan et al., 2017).

Existen estudios previos que concluyen que las comunidades microbianas de leche cruda pueden clasificarse según la altitud, observando una gran cantidad de Enterobacteriaceae, Corynebacterium, Staphylococcus y diversas especies de levaduras en las zonas altas (Bonizzi et al., 2009), situación que se estaría comprobando en la presente investigación donde la leche procede de sitio con alturas mayores a $2.000 \mathrm{~m} \mathrm{s.} \mathrm{n.} \mathrm{m.}$

\section{Conclusiones}

Se han cuantificado los microorganismos indicadores de calidad sanitaria (aerobios mesófilos, enterobacterias, Staphylococcus aureus y Salmonella) en la leche cruda del centro de acopio; evidenciando altos recuentos en todos los muestreos, lo que indica una deficiente calidad sanitaria de este producto, existiendo diferencias significativas entre los meses de la época de invierno en comparación con los meses de la época de verano.

\section{Agradecimientos}

A la Escuela Superior Politecnica del Chimborazo de Ecuador y a la Universidad de los Andes de Venezuela por el apoyo y la colaboración obtenida durante la ejecución de la investigación 


\section{Roles de autores}

- Ana Albuja Landi: conceptualización, curación de datos, investigación, metodología, recursos, redacción - borrador original.

- Sandra Escobar Arrieta: investigación, metodología, curación de datos.

- Felix Andueza Leal: validación, redacción - revisión y edición, supervisión.

\section{Referencias}

Acuerdo $\mathrm{N}^{\circ} 394$. Regular y controlar el precio del litro de leche cruda pagado en finca y/o centro de acopio al productor y promover la calidad e inocuidad de la leche cruda. Registro Oficial N ${ }^{\circ} 100,14$ de octubre de 2013. https://www.fao.org/faolex/results/details/fr/c/LEX-FAOC155259/

Albuja Landi, A., Escobar Arrieta, S., Guevara Iñiguez, L., Andueza Leal, F., Yugcha Pilamunga, P., \& Arguello Hernández, P. (2018). Resistencia antimicrobiana de Staphylococcus aureus aislados en quesos frescos artesanales elaborados en zonas rurales de Riobamba-Ecuador. Revista Perfiles, 20(2), 76-81. http://ceaa.espoch.edu.ec:8080/revista.perfiles/Articulos/Perfiles20Art9.pdf

Andueza-Leal, F. (2005). La leche y su importancia en la salud pública. Revista agropecuaria, 9, 28.

Arguelles, P., Escobar, S., Albuja, A., Espinoza, C., Portero, F., Fierro, A., Layedra, P., Ortiz, I., Araque, J., Lugo, A., Migrana, R., López-Merino, A., \& Andueza, F. (2015). Aislamiento de cepas bacterianas multirresistentes a diversos antimicrobianos en leche cruda bovina de la ciudad de Riobamba, Ecuador. VI Congreso Iberoamericano de Ciencias Farmacéuticas. Córdoba. Argentina. http://safe-digital.org/actacongreso.html

Artursson, K., Schelin, J., Thisted Lambertz, S., Hansson, I., \& Olsson Engvall, E. (2018). Foodborne pathogens in unpasteurized milk in Sweden. International Journal of Food Microbiology, 284, 120-127. https://doi.org/10.1016/j.ijfoodmicro.2018.05.015

Bonizzi, I., Buffoni, J. N., Feligini, M., \& Enne, G. (2009). Investigating the relationship between raw milk bacterial composition, as described by intergenic transcribed spacer-PCR fingerprinting, and pasture altitude. Journal of applied microbiology, 107(4), 1319-1329. https://doi.org/10.1111/j.1365-2672.2009.04311.x

Bramley, A. J., \& McKinnon, C. H. (1990). The microbiology of raw milk. In R. K. Robinson (ed.), Dairy microbiology, Vol. 1 (163-208). Elsevier Applied Science.

Chimborazo Ashqui, D. M. (2020). Control de calidad de un centro de acopio de leche cruda CA1, en la provincia de Chimborazo. Escuela Superior Politécnica de Chimborazo.

Chuquín Yépez, H. G., Aquino Ruíz, E. L., \& De la Cruz González, E. G. (2016). Diagnóstico del manejo de la calidad de leche y del queso en la Provincia del Carchi. SATHIRI, 11, 153-168. https://doi. org/10.32645/13906925.17

Contero, R., Requelme, N., Cachipuendo, C., \& Acurio, D. (2021). Quality of raw milk and payment system for quality in Ecuador. La Granja, 33(1), 31-43. https://doi.org/10.17163/LGR.N33.2021.03

Derakhshani, H., Fehr, K. B., Sepehri, S., Francoz, D., De Buck, J., Barkema, H. W., Plaizier, J. C., \& Khafipour, E. (2018). Invited review: Microbiota of the bovine udder: Contributing factors and potential implications for udder health and mastitis susceptibility. Journal of Dairy Science, 101(12), 10605-10625. https://doi.org/10.3168/jds.2018-14860

Doyle, C. J., Gleeson, D., O’Toole, P. W., \& Cotter, P. D. (2017). High-throughput metataxonomic characterization of the raw milk microbiota identifies changes reflecting lactation stage and storage conditions. International Journal of Food Microbiology, 255, 1-6. https://doi.org/10.1016/j.ijfoodmicro.2017.05.019

Fischer, W. J., Schilter, B., Tritscher, A. M., \& Stadler, R. H. (2011). Contaminants of Milk and Dairy Products: Contamination Resulting from Farm and Dairy Practices. In J. W. Fuquay (ed.), Encyclopedia of Dairy Sciences: Second Edition (pp. 887-897). Academic Press. https://doi.org/10.1016/B978-0-12374407-4.00104-7

Fusco, V., Chieffi, D., Fanelli, F., Logrieco, A. F., Cho, G. S., Kabisch, J., Böhnlein, C., \& Franz, C. M. A. P. (2020). Microbial quality and safety of milk and milk products in the 21 st century. Comprehensive Reviews in Food Science and Food Safety, 19(4), 2013-2049. https://doi.org/10.1111/1541-4337.12568

Giacometti, F., Serraino, A., Finazzi, G., Daminelli, P., Losio, M. N., Bonilauri, P., Arrigoni, N., Garigliani, A., Mattioli, R., Alonso, S., Piva, S., Florio, D., Riu, R., \& Zanoni, R. G. (2012). Foodborne pathogens in 
in-line milk filters and associated on-farm risk factors in dairy farms authorized to produce and sell raw milk in northern Italy. Journal of food protection, 75(7), 1263-1269. https://doi.org/10.4315/0362-028X. JFP-12-028

Godic-Torkar, K., \& Golc-Teger, S. (2008). The microbiological quality of raw milk after introducing the two day's milk collecting system. Acta Agriculturae Slovenica, 92(1), 61-74. https://www.dlib.si/details/ URN:NBN:SI:doc-52RUOPN7

Guarín Patarroyo, C. E., \& Restrepo Ochoa, D. A. (2020). Sobre la relación entre el consumo de leche cruda y la salud humana: una revisión sistemática. Revista Cubana de Alimentación y Nutrición, 30(2), 516-538. http://revalnutricion.sld.cu/index.php/rcan/article/view/1048

Guevara-Freire, D., Montero-Recalde, M., Rodríguez, A., Valle, L., \& Avilés-Esquivel, D. (2019). Calidad de leche acopiada de pequeñas ganaderías de Cotopaxi, Ecuador. Revista de Investigaciones Veterinarias del Perú, 30(1), 247-255. https://dx.doi.org/10.15381/rivep.v30i1.15679

Haran, K. P., Godden, S. M., Boxrud, D., Jawahir, S., Bender, J. B., \& Sreevatsan, S. (2012). Prevalence and characterization of Staphylococcus aureus, including methicillin-resistant Staphylococcus aureus, isolated from bulk tank milk from Minnesota dairy farms. Journal of Clinical Microbiology, 50(3), 688-695. https://doi.org/10.1128/JCM.05214-11

Hoque, M. N., Istiaq, A., Clement, R. A., Sultana, M., Crandall, K. A., Siddiki, A. Z. and Hossain, M. A. (2019). Metagenomic deep sequencing reveals association of microbiome signature with functional biases in bovine mastitis. Scientific Reports, 9(1), 1-14. https://doi.org/10.1038/s41598-019-49468-4

Jayarao, B. M., \& Henning, D. R. (2001). Prevalence of foodborne pathogens in bulk tank milk. Journal of Dairy Science, 84(10), 2157-2162. https://doi.org/10.3168/jds.S0022-0302(01)74661-9

Jiménez Velásquez, S. del C., Torres Higuera, L. D., Parra Arango, J. L., Rodríguez Bautista, J. L., García Castro, F. E., \& Patiño Burbano, R. E. (2020). Perfil de resistencia antimicrobiana en aislamientos de Staphylococcus spp. obtenidos de leche bovina en Colombia. Revista Argentina de Microbiología, 52(2), 121-130. https://doi.org/10.1016/J.RAM.2019.05.004

Kim, I. S., Hur, Y. K., Kim, E. J., Ahn, Y. T., Kim, J. G., Choi, Y. J., \& Huh, C. S. (2017). Comparative analysis of the microbial communities in raw milk produced in different regions of Korea. Asian-Australasian journal of animal sciences, 30(11), 1643-1650. https://doi.org/10.5713/ajas.17.0689

Kuhn, E., Meunier-Goddik, L., \& Waite-Cusic, J. G. (2018). Effect of leaving milk trucks empty and idle for $6 \mathrm{~h}$ between raw milk loads. Journal of Dairy Science, 101(2), 1767-1776. https://doi.org/10.3168/ jds.2017-13387

Lan, X. Y., Zhao, S. G., Zheng, N., Li, S. L., Zhang, Y. D., Liu, H. M., McKillip, J., \& Wang, J. Q. (2017). Short communication: Microbiological quality of raw cow milk and its association with herd management practices in Northern China. Journal of Dairy Science, 100(6), 4294-4299. https://doi.org/10.3168/ jds.2016-11631

Li, N., Wang, Y., You, C., Ren, J., Chen, W., Zheng, H., \& Liu, Z. (2018). Variation in raw milk microbiota throughout 12 months and the impact of weather conditions. Scientific reports, 8, 2371. https://doi. org/10.1038/s41598-018-20862-8

Lucey, J. A. (2015). Raw milk consumption: risks and benefits. Nutrition Today, 50(4), 189-193. https://oi. org/10.1097/NT.0000000000000108

Mallet, A., Gueguen, M., Kauffmann, F., Chesneau, C., Sesboue, A., \& Desmasures, N. (2012). Quantitative and qualitative microbial analysis of raw milk reveals substantial diversity influenced by herd management practices. International Dairy Journal, 27(1-2), 13-21. https://doi.org/10.1016/j.idairyj.2012.07.009

Millán, Y., Méndez, A., Burguera, M., Pimentel, P., Araque, M., \& Ramírez, A. (2018). Determinación de enterobacterias y detección de genes de virulencia en Escherichia coli aislada en leche cruda. Revista de La Sociedad Venezolana de Microbiología, 38(2), 58-63. http://saber.ucv.ve/ojs/index.php/rev_vm/ article/view/16260

Moreno Vásquez, F. C., Rodríguez Martínez, G., Méndez Mancera, V.M., Osuna Ávila, L. E., \& Vargas, M. R. (2007). Análisis microbiológico y su relación con la calidad higiénica y sanitaria de la leche producida en la región del Alto de Chicamocha (departamento de Boyacá). Revista de Medicina Veterinaria, 14, 61-83. https://ciencia.lasalle.edu.co/cgi/viewcontent.cgi?article=1105\&amp;context=mv

Neder, V. E., Canavesio, V. R., \& Calvinho, L. F. (2011). Presence of enterotoxigenic Staphylococcus aureus in bulk tank milk from Argentine dairy farms. Revista Argentina de microbiologia, 43(2), 104-106. https://doi.org/10.1590/S0325-75412011000200006 
Nero, L. A., \& De Carvalho, A. F. (eds.) (2018). Raw milk: balance between hazards and benefits. Academic Press. https://doi.org/10.1016/C2016-0-00282-6

Neviani, E., Bottari, B., Lazzi, C., \& Gatti, M. (2013). New developments in the study of the microbiota of raw-milk, long-ripened cheeses by molecular methods: the case of Grana Padano and Parmigiano Reggiano. Frontiers in microbiology, 4, 36. https://doi.org/10.3389/fmicb.2013.00036

Nogales, H., \& Granada, D. (2012). Guía de buenas prácticas pecuarias de producción de leche. Resolución Técnica $N^{\circ}$ 0217. AGROCALIDAD. https://www.agrocalidad.gob.ec/wp-content/uploads/2020/05/pecu3.pdf

Norma Técnica Ecuatoriana NTE INEN 1529-13:98. Control microbiológico de los alimentos. Enterobacteriaceae. Recuento en placa por siembra en profundidad.

Norma Técnica Ecuatoriana NTE INEN 1529-14. Control microbiológico de los alimentos. Staphylococcus aureus. Recuento en placa de siembra por extensión en superficie.

Norma Técnica Ecuatoriana NTE INEN 1529-15. Control microbiológico de los alimentos. Salmonella. Método de detección.

Norma Técnica Ecuatoriana NTE INEN 1529-2:2013. Control Microbiológico de los Alimentos. Toma, envío y preparación de muestras para el análisis microbiológico.

Norma Técnica Ecuatoriana NTE INEN 1529-5:2006. Control microbiológico de los alimentos. Determinación de la cantidad de microorganismos aerobios mesófilos.

Norma Técnica Ecuatoriana NTE INEN 9:2012. Leche cruda. Requisitos.

Ntuli, V., Njage, P., \& Buys, E. M. (2016). Characterization of Escherichia coli and other Enterobacteriaceae in producer-distributor bulk milk. Journal of Dairy Science, 99(12), 9534-9549. https://doi.org/10.3168/ jds.2016-11403

Oikonomou, G., Addis, M. F., Chassard, C., Nader-Macias, M., Grant, I., Delbès, C., Bogni, C. I., Le Loir, Y., \& Even, S. (2020). Milk Microbiota: What Are We Exactly Talking About?. Frontiers in microbiology, 11, 60. https://doi.org/10.3389/fmicb.2020.00060

Pacha, P. A., Munoz, M. A., González-Rocha, G., San Martín, I., Quezada-Aguiluz, M., Aguayo-Reyes, A., Bello-Toledo, H., \& Latorre, A. A. (2021). Molecular diversity of Staphylococcus aureus and the role of milking equipment adherences or biofilm as a source for bulk tank milk contamination. Journal of Dairy Science, 104(3), 3522-3531. https://doi.org/10.3168/jds.2020-19121

Pal, M., Mulu, S., Tekle, M., Pintoo, S. V., \& Prajapati, J. P. (2016). Bacterial contamination of dairy products. Beverage Food World, 43(9), 40-43.

Porcellato, D., Aspholm, M., Skeie, S. B., Monshaugen, M., Brendehaug, J., \& Mellegård, H. (2018). Microbial diversity of consumption milk during processing and storage. International journal of food microbiology, 266, 21-30. https://doi.org/10.1016/j.ijfoodmicro.2017.11.004

Portilla Farfán, F. (2018). Agro climatología del Ecuador (1. ${ }^{a}$ ed.). Editorial Abya-Yala.

Pyz-Łukasik, R., Paszkiewicz, W., Tatara, M. R., Brodzki, P., \& Bełkot, Z. (2015). Microbiological quality of milk sold directly from producers to consumers. Journal of Dairy Science, 98(7), 4294-4301 https://doi. org/10.3168/jds.2014-9187

Quigley, L., O’Sullivan, O., Stanton, C., Beresford, T. P., Ross, R. P., Fitzgerald, G. F., \& Cotter, P. D. (2013). The complex microbiota of raw milk. FEMS microbiology reviews, 37(5), 664-698. https://doi. org/10.1111/1574-6976.12030

Ramírez Robles, M. M., \& Lluman Marcatoma, P. L. (2020). Evaluación de la calidad fisicoquímica y microbiológica de la leche cruda almacenada en centros de acopio de la provincia de Chimborazo. Escuela Superior Politécnica de Chimborazo.

Requelme, N., \& Bonifaz, N. (2012). Caracterización de sistemas de producción lechera de Ecuador. La Granja, 15(1), 55-69. https://doi.org/10.17163/lgr.n15.2012.05

Reuben, R. C., Roy, P. C., Sarkar, S. L., Rubayet Ul Alam, A., \& Jahid, I. K. (2020). Characterization and evaluation of lactic acid bacteria from indigenous raw milk for potential probiotic properties. Journal of dairy science, 103(2), 1223-1237. https://doi.org/10.3168/jds.2019-17092

Skeie, S. B., Håland, M., Thorsen, I. M., Narvhus, J., \& Porcellato, D. (2019). Bulk tank raw milk microbiota differs within and between farms: A moving goalpost challenging quality control. Journal of dairy science, 102(3), 1959-1971. https://doi.org/10.3168/jds.2017-14083

Villar, A., García, J. A., Iglesias, L., García, M. L., \& Otero, A. (1996). Application of principal component analyses to the study of microbial populations in refrigerated raw milk from farms. International Dairy Journal, 6(10), 937-945. https://doi.org/10.1016/S0958-6946(96)00005-2 